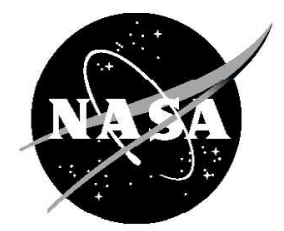

\title{
Large-Eddy Simulation: Current Capabilities, Recommended Practices, and Future Research
}

Nicholas J. Georgiadis

Glenn Research Center, Cleveland, Ohio

Donald P. Rizzetta

Air Force Research Laboratory, Wright-Patterson Air Force Base, Dayton, Ohio

Christer Fureby

FOI, Swedish Defense Research Agency, Stockholm, Sweden 


\section{NASA STI Program . . . in Profile}

Since its founding, NASA has been dedicated to the advancement of aeronautics and space science. The NASA Scientific and Technical Information (STI) program plays a key part in helping NASA maintain this important role.

The NASA STI Program operates under the auspices of the Agency Chief Information Officer. It collects, organizes, provides for archiving, and disseminates NASA's STI. The NASA STI program provides access to the NASA Aeronautics and Space Database and its public interface, the NASA Technical Reports Server, thus providing one of the largest collections of aeronautical and space science STI in the world. Results are published in both non-NASA channels and by NASA in the NASA STI Report Series, which includes the following report types:

- TECHNICAL PUBLICATION. Reports of completed research or a major significant phase of research that present the results of NASA programs and include extensive data or theoretical analysis. Includes compilations of significant scientific and technical data and information deemed to be of continuing reference value. NASA counterpart of peer-reviewed formal professional papers but has less stringent limitations on manuscript length and extent of graphic presentations.

- TECHNICAL MEMORANDUM. Scientific and technical findings that are preliminary or of specialized interest, e.g., quick release reports, working papers, and bibliographies that contain minimal annotation. Does not contain extensive analysis.

- CONTRACTOR REPORT. Scientific and technical findings by NASA-sponsored contractors and grantees.
- CONFERENCE PUBLICATION. Collected papers from scientific and technical conferences, symposia, seminars, or other meetings sponsored or cosponsored by NASA.

- SPECIAL PUBLICATION. Scientific, technical, or historical information from NASA programs, projects, and missions, often concerned with subjects having substantial public interest.

- TECHNICAL TRANSLATION. Englishlanguage translations of foreign scientific and technical material pertinent to NASA's mission.

Specialized services also include creating custom thesauri, building customized databases, organizing and publishing research results.

For more information about the NASA STI program, see the following:

- Access the NASA STI program home page at http://www.sti.nasa.gov

- E-mail your question via the Internet to help@ sti.nasa.gov

- Fax your question to the NASA STI Help Desk at $443-757-5803$

- Telephone the NASA STI Help Desk at 443-757-5802

- Write to: NASA Center for AeroSpace Information (CASI) 7115 Standard Drive Hanover, MD 21076-1320 
NASA/TM-2009-215616

AIAA-2009-948

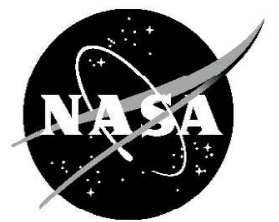

\section{Large-Eddy Simulation: Current Capabilities, Recommended Practices, and Future Research}

Nicholas J. Georgiadis

Glenn Research Center, Cleveland, Ohio

Donald P. Rizzetta

Air Force Research Laboratory, Wright-Patterson Air Force Base, Dayton, Ohio

Christer Fureby

FOI, Swedish Defense Research Agency, Stockholm, Sweden

Prepared for the

47th Aerospace Sciences Meeting

and sponsored by American Institute of Aeronautics and Astronautics

Orlando, Florida, January 5-8, 2009

National Aeronautics and

Space Administration

Glenn Research Center

Cleveland, Ohio 44135 


\section{Acknowledgments}

The authors are grateful to members of the AIAA Fluid Dynamics Technical Committee Large Eddy Simulation (LES) Working Group who contributed to the development of this article, and in particular to J.R. DeBonis, B.R. Smith, G.A. Blaisdell, and F. Ladeinde. They also wish to acknowledge M.R. Visbal and P.E. Morgan for useful conversations on LES.

This work was sponsored by the Fundamental Aeronautics Program at the NASA Glenn Research Center.

Level of Review: This material has been technically reviewed by technical management.

Available from

NASA Center for Aerospace Information 7115 Standard Drive

Hanover, MD 21076-1320
National Technical Information Service 5285 Port Royal Road Springfield, VA 22161

Available electronically at http://gltrs.grc.nasa.gov 


\title{
Large-Eddy Simulation: Current Capabilities, Recommended Practices, and Future Research
}

\author{
Nicholas J. Georgiadis \\ National Aeronautics and Space Administration \\ Glenn Research Center \\ Cleveland, Ohio 44135 \\ Donald P. Rizzetta \\ Air Force Research Laboratory \\ Wright-Patterson Air Force Base \\ Dayton, Ohio 45433 \\ Christer Fureby \\ FOI \\ Swedish Defense Research Agency \\ Stockholm, Sweden
}

\begin{abstract}
This paper presents the results of an activity by the Large Eddy Simulation (LES) Working Group of the AIAA Fluid Dynamics Technical Committee to (1) address the current capabilities of LES, (2) outline recommended practices and key considerations for using LES, and (3) identify future research needs to advance the capabilities and reliability of LES for analysis of turbulent flows. To address the current capabilities and future needs, a survey comprised of eleven questions was posed to LES Working Group members to assemble a broad range of perspectives on important topics related to LES. The responses to these survey questions are summarized with the intent not to be a comprehensive dictate on LES, but rather the perspective of one group on some important issues. A list of recommended practices is also provided, which does not treat all aspects of a LES, but provides guidance on some of the key areas that should be considered.
\end{abstract}

\section{Introduction}

Until recently, Reynolds-averaged Navier Stokes (RANS) methods were used almost exclusively for the computational fluid dynamics (CFD) analysis of turbulent flows for practical engineering problems. RANSbased techniques are on one end of the spectrum of turbulent calculation methods, in which all turbulent fluid dynamic effects are replaced by a turbulence model. On the other end of the spectrum, Direct Numerical Simulation (DNS) methods calculate the entire turbulent energy spectrum by resolving all turbulent motions. Although this avoids the limitations associated with turbulence modeling, DNS methods will remain computationally impractical in the foreseeable future for all but the simplest configurations. Large-Eddy Simulation (LES) methods, which directly calculate the large-scale turbulent structures and reserve modeling only for the smallest scales, may offer the best prospects for improving the fidelity of turbulent flow simulations. A related approach is the group of hybrid RANS/LES methods, where RANS is used in regions where the turbulence is in equilibrium, such as in wall boundary layers, and LES is used where non-equilibrium occurs, typically away from walls.

In recent years, LES has seen an increase in usage for flows, where previously RANS methods were typically applied, for the following reasons: (1) rapid increases in computing power, memory, and storage, (2) realization that RANS methods inherently cannot handle certain classes of complex turbulent flow problems such as massively separated flows, (3) the availability of LES and hybrid RANS/LES methods in production class CFD codes. With this increased use of LES by more CFD practitioners, questions have arisen concerning the proper usage of LES, the level of solution fidelity that can be expected, and areas of method development that are needed to improve the utility of the technique. 
This paper will provide the results of an effort conducted by the Large Eddy Simulation (LES) Working Group of the AIAA Fluid Dynamics Technical Committee (FDTC) to assess the current status of LES, provide recommendations for future work, and provide a list of recommended practices and key considerations. Within the definition of "LES" used here we include hybrid RANS/LES methods. While an attempt is made here to address broad topics in LES, it is impossible to address every important issue within the scope this document. Further, much of the document represents opinions of the authors and the LES Working Group that contributed to this effort. As a result, these suggestions are not intended to be a comprehensive dictate on LES, but rather the perspective of one group on some important issues in LES and how the field may move forward in the future.

\section{Current Capabilities of LES}

To address the current capabilities of LES and identify limitations that require more work, a survey was posed to participants of the LES Working Group. In this section, the survey questions posed to this group are described and a summary of the responses is provided. For some of the questions, a consensus was reached on particular topics related to LES, but for other questions, a broad range of opinions resulted. This indicates that for certain areas in LES, there is not enough knowledge or experience in place to determine the merits of certain approaches (e.g. subgrid modeling) and more work is needed. The intent of the survey was to draw responses from a group that are representative of the broader community already using or considering usage of LES-based methods for turbulent flow simulations. The participants in the survey are listed in Table 1 and comprise industry, government, and academic interests.

It is suggested that the interested reader may also consider review articles such as the overviews of LES provided by Moin and Kim, ${ }^{1}$ Lesieur and Metais, ${ }^{2}$ Pope, ${ }^{3}$ Boris, ${ }^{4}$ Boris et al.,${ }^{5}$ Reynolds, ${ }^{6}$ and Spalart. ${ }^{7,8}$ The article by Pope also considers a list of questions related to LES with the intent, as he states, to "raise some fundamental questions concerning the conceptual foundations of LES and about the methodologies and protocols used in its application." The focus of the questions considered in this paper is a bit different, with the objective being to address the current status of LES as applied to turbulent flow simulations.

\begin{tabular}{c|l} 
Contributor & Organization \\
\hline Greg Blaisdell & Purdue University \\
Alan Cain & Innovative Technologies Applications Company, Inc. \\
Meelan Choudhari & NASA Langley Research Center \\
James DeBonis & NASA Glenn Research Center \\
Jack Edwards & North Carolina State University \\
Christer Fureby & Swedish Defense Agency - FOI \& Chalmers University of Technology \\
Nicholas Georgiadis & NASA Glenn Research Center \\
Won Wook Kim & Pratt and Whitney \\
Foluso Ladeinde & TTC Technologies, Inc. \\
Mori Mani & The Boeing Company \\
Ugo Piomelli & Queen's University \\
Donald Rizzetta & United States Air Force Air Force Research Laboratory \\
Christopher Roy & Virginia Polytechnic Institute and State University \\
Christopher Rumsey & NASA Langley Research Center \\
Brian Smith & Lockheed Martin Aeronautics Company \\
Paul Tucker & Cambridge University \\
Z.J. Wang & Iowa State University
\end{tabular}

Table 1. LES Working Group Survey Participants

In discussions of the LES Working Group following collection of these responses, it was considered to solicit additional responses from LES researchers that may have more expertise in a particular area than any of the contributors did. This was not done in order to complete this activity in a reasonable time period. 
However, opinions that differ from those that follow would certainly be welcomed, and would be very helpful in raising attention to issues related to LES that currently do not have definitive answers. The following discussion is organized as follows: Each of the eleven questions posed to the LES Working Group participants are stated followed by a summary of the responses. Some recommendations for future research are included in these responses. The last section of this paper will summarize future research needs identified via these survey questions. The reader should note that while we have attempted to provide some key references of relevance to the subsequent discussion, these should only be considered a sampling of a much larger volume of informative articles available.

Question 1: What is your interest in LES and its cousins (hybrid RANS/LES methods)? For example - you are already using it for some form of simulations, you are doing research in LES method development, and/or you are thinking that the practical use of LES for problems of your interest may not be that far away.

There is broad interest in using LES for aeroacoustic simulations, in particular predicting jet noise emitted by aircraft engines. Older jet noise prediction methods utilizing RANS methods are limited not only by the quality of the jet aerodynamic prediction, but also by the subsequent steps required to extrapolate a RANS mean flow solution to a predicted noise field via an acoustic analogy which also has significant uncertainty. The attractiveness of LES for jet noise prediction is that it is believed that the largest turbulent scales in the jet plume drive the noise generation. Because these largest scales can be calculated directly, there is no subsequent approximation to obtaining the predicted noise field. LES is also being used for aeroacoutics applications such as predicting the noise fields emitted from landing gear, cavities, and high-lift devices on wings.

In another area of aero-propulsion application, LES has also found significant new interest in predicting combustor flow fields where the flows are characterized by turbulent velocity magnitudes that are in many cases on the order of the mean flow velocity. Capturing the large mixing scales have provided significant difficulties for RANS methods, but as for the jet noise problem, LES is considered appropriate for the combustor simulation class of problems because of the dominance of large scale turbulence. In the field of hypersonic propulsion, there has not been a great deal of usage to date, but the limitations of RANS-based methods are now prompting the exploration of LES-based methods. For these flows, RANS has difficulties in not only predicting the momentum transport in a highly compressible flow environment, but also in the prediction of the turbulent scalar transport, namely that of thermal energy and species mixing.

Other areas in which the survey respondents indicated interest in LES include simulations of flows involving large separations or wakes, where no RANS-based methods have been shown to provide reliable predictions. These include a very broad range of applications including wake flows induced by human motion, truck and other vehicle aerodynamics, ship and submarine hydrodynamics, electronics cooling, and room ventilation. LES is also receiving interest, in particular in the industrial application environment, for multidisciplinary problems including aero-structural, aero-optic, and aero-elastic analysis techniques. Finally, LES is receiving attention for application to active flow control problems where the time resolved behavior of flows involving large scale turbulence has proved to be insurmountable for RANS, but seems to be a good fit for the philosophy of LES.

\section{Question 2: How do you think LES is being used successfully today and who is doing it?}

Prior to about a decade ago, LES was used successfully to investigate the details of flow problems having relatively simple geometry and at low Reynolds numbers. While use of LES in such an academic or fundamental setting continues today, probably the most significant work presently being conducted for more complex configurations having flow characteristics where steady-state RANS methods have failed. As a result, the survey responses to this question were naturally very much in line with those of question 1 . In terms of who is doing this work, generally it is persons with significant experience, appropriate computational tools, and available computing power for LES simulations. While some envision LES as becoming a design tool that can be employed by persons without extensive years of experience concentrating on LES techniques, this will not be the case for the foreseeable future.

In terms of specific applications of promising LES usage, we provide some examples by refering to a series of papers that were presented in two special technical sessions organized by the LES Working Group of the AIAA Fluid Dynamics Technical Committee at the 2008 AIAA Aerospace Sciences Meeting and subsequently 
published in the journal Progress in Aerospace Sciences. These papers provide numerous examples of where LES is being used appropriately today (along with identification of outstanding LES modeling issues) and also in all cases have significant reference lists that the interested reader may explore to obtain more specifics. We provide an overview of these papers next.

A broad overview of conventional LES approaches that are in use today for application to engineering flows is provided by Fureby. ${ }^{9}$ This paper begins with a presentation of newer LES technologies that have recently received attention followed by a description of numerical methods for implementing unstructured schemes in LES solvers. Several example cases that have been investigated by the author are presented. These range from relatively simple benchmark flows to complex geometries in aeronautical and marine applications. The topics of error and uncertainty quantification are also addressed. The paper concludes with a discussion of practical issues in using LES for engineering flow applications.

An article by Rizzetta, Visbal, and Morgan ${ }^{10}$ demonstrates application of an LES approach developed by the authors over several years to active flow control problems. The nature of these problems cannot be modeled accurately with RANS-based techniques because of the inherent unsteadiness in the flows. The authors utilize a high order compact scheme in their simulations and a Pade-type spatial filter with no explicit subgrid model. Several flow control examples are provided, including plasma-based flow control utilized in a turbine application.

LES has received significant attention for the calculation of jet noise, as described by Tucker. ${ }^{11}$ Jet noise prediction is one category of flow problems for which LES has been expected to offer significantly greater accuracy than RANS-based methods. Not only do RANS based methods have difficulties in calculating the fluid dynamics associated with jets issuing from complex nozzle configurations, but calculating the noise requires a subsequent approximation, termed the acoustic analogy, to extrapolate the RANS predicted flow to noise emitted by the jet. In contrast, LES can be used to directly calculate the large scale pressure fluctuations which produce acoustic waves. Tucker addresses some of the key issues involved in applying LES to jets and the nozzles from which the jets originate. Variants on LES, such as Monotonically-Integrated LES (MILES) and Numerical LES (NLES) are discussed. Other recent papers providing overviews of LES as applied to jet noise prediction are presented in Refs. 12-14.

Piomelli explains the challenges in using LES for wall bounded flows at Reynolds numbers of engineering interest in Ref. 15. A novel approach to overcoming this obstacle is presented in which the outer regions of boundary layers are calculated with LES while near wall regions are modeled by one of three techniques. The pros and cons of each of these techniques are discussed and recommendations for further work to advance wall layer models is presented.

The challenges of calculating flow problems involving shock wave / turbulent boundary layer interactions (SWTBLIs) is detailed by Edwards. ${ }^{16}$ This class of problems is another for which RANS methods have been particularly deficient. Significant three-dimensional flow features are present even in problems that are two-dimensional in the mean. A comprehensive survey of approaches including DNS, LES, and hybrid RANS/LES is discussed, with emphasis placed on the compression corner interaction problem. It is shown that there is promise for these time-resolved techniques to better calculate some of the complex fluid physics for SWTBLIs. Suggestions for future research efforts are made.

Pitsch addresses the use of LES for the prediction of reacting flows, with emphasis placed on aircraft engine combustors in Ref. 17. Primary fuel atomization, subfilter scalar mixing, and determination of pollutant formation are discussed as three chief challenges in applying LES to reacting flows. As mentioned previously in this introduction, the argument has been made that alternatives to explicit subrgid modeling may be acceptable for simulation of some flows. Pitsch shows that subgrid scale modeling is essential for reacting flows because chemical reactions occur at a very small scale and the subsequent heat release affects the large scale motion. Another recent overview of the use of LES for combustor simulations is given by Fureby. ${ }^{18}$ While there has not been extensive use of LES for supersonic combustion applications, an article by Berglund et al. ${ }^{19}$ addresses current capabilities of LES employing finite rate chemistry for scramjet simulations. 
Question 3: How do you think LES is not being used appropriately today? Are there too many papers/efforts out there that attempt LES but are not using appropriate resolution? A related question is what do you think of the overall quality of papers on LES today? Consider (1) papers at conferences you have attended recently, (2) articles in journals you have read.

While there is a lot of promising work in the area of LES advancement and applications, and correspondingly good papers documenting this work, there does appear to be a large number of simulations that are claiming to be LES, but probably represent a misuse of the method. In general, papers that have been published in journals have a better chance than conference papers to reflect appropriate usage of LES because of the additional peer review process.

Part of the problem of low quality LES is the availability of LES and hybrid RANS/LES methods in many broadly used CFD codes. When attempting an LES, it is quite satisfying to be able to construct an animation of a time-varying flow that looks like a turbulent flow. However, this offers no guarantee that the appropriate grid resolution has been used, spatial and temporal schemes have been selected, boundary conditions (such as time-varying inflow conditions correctly representing the turbulent inflow state) have been set properly, or that the simulation has been run long enough. Yet all of these factors can lead to significant variations in the flow quantities that the analyst was hoping the LES could provide accurately.

To the uninformed, simply selecting the LES option in a code may seem to be a better option than any RANS capability, even using a grid designed for RANS. However, for some classes of flows, such as attached wall boundary layers at higher Reynolds numbers, a RANS solution may still yield certain engineering quantities such as mean flow velocity profiles or overall viscous drag, more accurately than an LES. The responses to the survey also expressed the need to provide guidance to potential LES users of the key issues and appropriate simulation techniques for certain classes of flows. A latter section of this paper attempts to provide guidance on some areas of importance to the quality of an LES.

Question 4: What kind of flows can be properly simulated today using LES with available computational resources? For example, particular classes of flows such as jets, flows with massive separations, wall-bounded flows, chemically reacting flows. Maybe also consider Reynolds number and other scaling/complexity limitations. Where is LES being pushed as a replacement for RANS where it is not yet ready?

The classes of flow problems described in the responses to questions 1 and 2 are those that generally have the most promise to be simulated using computational resources available today. However, one must consider that "available computational resources" may be a single processor computer to one user and one with thousands of processors to another. In an attempt to generalize the flows for which LES is currently a viable option, one may identify the previous flows as being dominated by large scale turbulence, away from significant wall effects. This is also not always a clear cut issue, however, as one may see by considering the jet plume problem. While the large energy containing scales exist in the free shear layer away from walls, these mixing layers originate from nozzles for which the boundary layers may have an effect on the developing shear layer.

Capturing wall effects at appreciable Reynolds numbers with an LES approach still appears to be somewhat out of reach, but there is research underway to develop wall layer models (e.g. Ref. 15) that may help bridge this gap. Flows involving SWTBLIs are another class of problems where LES work of just a few years ago seemed to offer no improvement over RANS methods. Recent work such as that of Edwards ${ }^{16}$ has shown that while LES is not the clear winner for predicting engineering quantities such as wall skin friction and mean velocity profiles, LES is able to provide insight into key mechanisms such as the three-dimensional flow structures that are characteristic of otherwise two-dimensional shock-wave boundary layer geometries.

Question 5: More and more general purpose codes (originally designed for RANS) are now including some form of LES capability. What are the benefits/potential dangers in this? Are upwinded schemes a good option for LES?

A large number of general purpose CFD codes available to a broad user community, including commercial software packages, government-developed codes, and industry codes, have implemented LES-based capabilities in recent years, especially hybrid RANS/LES methods. The overall impression of the LES WG participants is that offering these capabilities may be beneficial in extending LES methods to a broader usage base, but with this there is also significant potential for misuse by inexperienced users. 
Calculation of turbulent flows is only one example of computational physics in which new models have historically drawn interest and raised the hope that the new model will result in improved solution fidelity for the user. This has been the case for many years with RANS modeling where a new formulation would be published and the promise of improving solutions across the spectrum of all turbulent flow problems would be raised, even if the improvements were tailored to improve prediction of only a small class of flows. With the rate of new RANS model development slowing in recent years, hybrid RANS/LES methods have in many cases taken over the role of being the new turbulence modeling approach promising to deliver better solutions.

When used with care, LES and hybrid RANS/LES can provide better predictions of certain turbulent flows than was possible with RANS. The problem, however, is that frequently there is little guidance available on the proper usage of these new methods and subsequently little care taken by novice users to assure that their usage of an LES-based method is rigorous enough to generate confidence in the solutions obtained. It is not difficult to turn on the LES or hybrid RANS/LES option in many of these general purpose codes. Selection of a turbulence model that can be applied as a subgrid model in LES regions, and running in time-accurate mode is frequently all that is needed for a user to get a calculation running. There is no provision to require attention be given to important issues such as grid design, subgrid and wall models, numerical methods, and boundary conditions to allow a solution to proceed. As a solution progresses, the ability to generate animations of flows with turbulent looking unsteady features such as vortex shedding and turbulent eddy evolution provides feedback to the user that the correct physics are being reproduced, even if this is not the case.

It is easy to understand that offering some form of LES-based simulation capability is required for CFD codes, especially those from commercial vendors, to appear to be keeping up with the state-of-theart. However, education of new users on proper utilization of LES is required to help them make the best choices in turbulent simulation methods and to also be aware of the key issues they must address in setting up a simulation problem. For LES, this includes construction of grids designed much differently than would have been done for RANS, the selection of numerical methods different from those commonly used in RANS, creation of appropriate boundary conditions, knowledge of when to start an averaging procedure to assemble mean flow and turbulent statistics, and several other issues. The "Recommended Practices and Key Considerations for LES" section of this paper attempts to provide some key guidelines for users to consider. Other papers, such as that by Spalart ${ }^{20}$ provide guidelines that should help newer users interested in LES and related methods.

Almost all production-type RANS solvers employ upwinded methods. The question of whether upwinded methods can be used for LES is one that has drawn a broad range of responses from not only this LES WG but also the larger aerospace and fluid dynamics community. Newer approaches like Implicit LES have gained wider acceptance, because for complex flow problems, the interaction of convection scheme numerics, subgrid modeling, and filtering becomes less clear. References 21 and 22 address this issue in a broad context using the concept of Modified Equation Analysis to connect the numerical methods to the subgrid models.

Earlier efforts in LES mandated the use of numerical schemes having both low and definable diffusion and dispersion characteristics. Methods with clearly definable cut-off wave numbers were desirable, and it was expected that an explicit subgrid model was required to exclusively handle the range of the turbulence spectrum between that resolved by the numerical scheme and the Kolmogorov scale. For very simple, low Reynolds number canonical flows, the literature made a strong case for these requirements to be strictly followed. As such, upwinded methods with their inherent dissipation appeared to certainly be a bad choice for LES simulations.

However, as LES and hybrid RANS/LES methods have been applied to more complex flows of engineering importance, where geometries and flow conditions have made adherence to these rules extremely difficult and the knowledge of the exact cutoff scale impossible to determine, upwinding is no longer considered a far-fetched option. Low-order upwinding methods likely contaminate turbulent structures too much to be considered a legitimate option, but there are a number of higher-order upwinding methods for which quality LES simulations have been obtained. Further, for flows containing abrupt discontinuities such as shock waves, the utility of upwinded methods over central-based schemes is clear in maintaining solution stability. For such flows, work into advanced numerical methods such as that of Yee et al. ${ }^{23}$ has resulted in schemes that have central-like behavior except in regions of the flow where there are very abrupt gradients, and the scheme is able to adjust to having upwinded behavior. 
Question 6: What kind of sensitivity to grid resolution (and other simulation factors - subgrid modeling, fidelity of numerical scheme) should we expect from LES studies?

In steady-state RANS simulations, it is frequently the expectation and for journal submissions a requirement to demonstrate "grid convergence" or insensitivity of the solution to further grid refinement. Such grid convergence is usually not possible in LES, however. As a finer grid is utilized, a greater fraction of the turbulence spectrum is directly calculated as opposed to being modeled by an explicit or implicit subgrid model. It is generally agreed that an important requirement for constructing an appropriate grid is to ensure that the cut-off wavenumber is in the inertial subrange, especially in the primary regions of interest in the simulation.

While achieving complete grid indepedence may not be practical for problems of engineering interest, producing substantially different solutions with grids of different resolution would result in very little confidence being placed in the results. Ideally, a rigorous LES simulation should show sensitivity not only to grid density, but also to grid stretching, time discretization, subgrid modeling, boundary conditions, and other factors. As LES becomes more widely used, there is a tradeoff between concentrating on the rigor of the simulations and delivering solutions to make engineering decisions. At a minimum it should be expected that examination of these modeling parameters be performed for any LES, with an identification of potential sources of errors and an estimation of the error bounds.

Question 7: What do you think about the capabilities for utilizing unstructured grids for LES? Are the challenges in getting higher-order unstructured methods a major limitation?

Unstructured grid methods have become much more prevalent in recent years for RANS simulations because of the utility in creating grids for complicated geometries. Exploration of unstructured methods for LES has increased recently as well. An overview of the use of LES using unstructured methods is provided in Ref. 24. An example of successful use of unstructured hybrid RANS/LES applied to a complete aircraft simulation is provided in Ref. 25. In this case, the magnitude of the turbulent eddies was on the order of the size of the aircraft, where a hybrid RANS/LES method may be expected to do much better than a RANS only technique.

It is generally believed that the primary challenge in utilizing unstructured grids for LES is the difficulty in deriving higher-order unstructured schemes. There has been promising work in developing techniques such as spectral volume ${ }^{26}$ and discontinuous Galerkin ${ }^{27}$ techniques for application to higher-order unstructured grid methods. One attractive aspect of the discontinuous Galerkin approach for LES is the ability to do "P" refinement (i.e. order of accuracy) on a fixed grid which may provide some measure of accuracy. An overview of higher-order flux-limiting based unstructured methods for implicit LES is presented in Drikakis et al. ${ }^{21}$

In addition to the challenges in obtaining higher-order unstructured grid methods appropriate for LES, other issues such as the effects of different grid topologies (i.e. prismatic versus tetrahedral), rapidly changing grid volumes, and non-conservative reconstructions are also recognized as likely important to LES. However, there has not been a lot of research performed in this area to provide definitive guidance for the user community.

Question 8: What methods for specifying inflow boundary conditions are promising right now and what work is needed?

It is generally accepted that specification of the unsteady turbulent state is required at the inflow of an LES. For some flows where turbulence in the area of interest is primarily driven by some physical feature such as a large scale bluff body separation, the impact of not precisely specifying the inflow turbulence may not be large. However, there is still the risk or misrepresenting the transport of turbulence in the area of interest. There are several methods for generating turbulent inflow conditions including (1) recycling/rescaling, (2) introducing artificial perturbations about the mean flow, (3) complete time-varying inflow profiles, and (4) perturbing/tripping the inflow region. A discussion of these techniques appears in the "Recommended Practices and Key Considerations for LES" section of this report. 
Question 9: For what types of problems are differences in subgrid models important? What are your comments on implicit subgrid models?

In the response to question 5, it was mentioned that early LES work examined relatively simple problems, such as channel flows and decaying turbulence, for which it was relatively straightforward to identify the cut-off wave number associated with a particular numerical scheme and associated filter. As a result, the role of the subgrid model and range of scales for which it was expected to operate over was also relatively well defined. However, as LES and hybrid RANS/LES methods have been attempted for more demanding flows and complex geometries, the exact influence of dissipation provided by the subgrid model and that provided by the numerical scheme is not so easy to determine.

For flows where the resolved turbulent near-wall behavior is crucial, subgrid model specifics are still an important consideration. This is true for pure LES simulations and for hybrid RANS/LES simulations, where behavior in the interface regions between RANS and LES, can be particularly sensitive to choice of underlying turbulence model. The issues related to hybrid RANS/LES modeling in the interface regions are discussed in question 10. Subgrid modeling specifics are also important to problems involving physical processes occurring on scales smaller than can be resolved, such as combustion and multiphase flows.

For flows where the details of the resolved turbulent near-wall behavior is not the primary concern, it appears that the specifics of the subgrid model may not be so important. However, this is not to say that any subgrid model, explicit or implicit, can then be expected to guarantee good results. Further, the analyst should be aware of the interaction of the subgrid model choice, numerical scheme, and any other feature of the simulation that provides dissipation to the time-evolving solution.

Interest in implicit subgrid models or Implicit LES (ILES) has grown substantially in recent years. Acceptance of the method has accompanied the realization that for many flows, it is not easy to isolate the specific contributions of convection scheme numerics, subgrid modeling, and filtering. In ILES, unresolved scales are treated not by an explicit subgrid model, but implicitly through specific and carefully-made reconstruction of the convective fluxes. Some recent overview papers demonstrating the successful use of ILES using non-oscillatory finite volume (NFV) numerical schemes are provided in Refs. 28-30. More discussion of the origin of ILES is provided in the "Recommended Practices and Key Considerations for LES" section of this paper under "Subgrid Modeling."

Question 10: What is your opinion of hybrid methods that promise a continuous applicability from the RANS limit to the LES limit?

For the last decade, the interest in and usage of hybrid RANS/LES models has grown rapidly. Within the class of hybrid RANS/LES models, a number of approaches have been proposed in recent years as discussed in the comprehensive review by Leschziner. ${ }^{31}$ Here we will consider two primary families of approaches that have evolved in recent years. In one approach, RANS and LES equations are solved in demarcated regions and turbulence in the LES regions is initiated by some dominant unsteady flow feature, such as a massively separated flow. Perhaps the most widely used such technique is the Detached-Eddy Simulation (DES) method originally proposed by Spalart. ${ }^{32}$ The RANS regions are only expected to provide mean flow quantities to the LES regions. Several extensions to the original formulation have been proposed including a recent update by Spalart ${ }^{33}$ called Delayed DES, or DDES. In the other family of hybrid RANS/LES approaches, a continuous application from RANS to LES is sought. One turbulence model is utilized and is expected to adjust to the level of resolution. The primary question here is whether two analysis techniques developed from very different assumptions can be solved in such a closely-coupled manner.

One of the earliest published papers proposing the possibility of a single turbulence model being able to serve from the RANS limit on one end of the spectrum of turbulent calculations methods to DNS on the other end was by Speziale. ${ }^{34}$ More recently, the Partially-Averaged Navier-Stokes (PANS) method has been proposed by Girimaji, ${ }^{35}$ in which a single turbulence model is used and whether the model is serving as a RANS closure, subgrid scale model, or somewhere in between is determined by the level of grid resolution and a constant preset by the user for a particular simulation. There are several other approaches that also attempt to provide continuous closure to turbulent simulations from RANS regions through the interface regions to LES regions such as those of Refs. 36 and 37.

While developing a model that may work in the RANS limit, LES limit, and also in the interface region sounds highly desirable, it is not clear that such a model is possible particularly in the interface region. The reason for this is the fundamentally different nature of how the RANS and LES equations are derived and 
their computational behavior. The RANS equations assume that a time average much greater than any turbulent time scale was utilized and turbulent stresses are replaced by their averaged effect. In practice, an eddy viscosity is typically used which results in a flow that is computationally very stable in highly turbulent regions due to the effective viscosity which can be orders of magnitude larger than the molecular viscosity. In contrast, the LES equations are derived using a spatial filter that separates the scales that can be directly calculated from those that must be modeled. Computationally the subgrid stresses, also frequently replaced with use of an effective eddy viscosity, fundamentally cannot be so large as to artificially damp the growth and transport of the large scale eddies that the LES is designed to capture. In the interface regions, the modeled turbulent stress can easily become too large to maintain the unsteady turbulent features desired by an LES, but not large enough to replace all turbulent stresses with an effective Reynolds-averaged state. The result is that this interface region is likely not treated consistently and further, the invalid turbulent stresses can readily contaminate the surrounding LES regions.

Despite these concerns, it is possible that hybrid RANS/LES models, including those suggesting a continuous applicability, may help extend the utility of a RANS simulation for flows where RANS-only fails. There have been some recent methods proposed that recognize the importance of the interface region treatment. These include techniques that introduce fluctuations into the LES region (Refs. 37-40), and incorporating mean stresses from the time-averaged LES back into the RANS regions (Refs. 41 and 42). Without question, the treatment of the RANS/LES interface remains an area of needed research.

Question 11: For what flows is there good quality experimental data available for LES validations/verification? What kind of problems do you think new experiments would be valuable?

There are several high-quality DNS and experimental studies that can be used for validation of LES for many simple configurations at low Reynolds numbers. There have been extensive efforts such as that by the European Research Community on Flow, Turbulence, and Combustion (ERCOFTAC) to assemble databases used for validation of turbulent flow simulation techniques. However, as LES begins to be used for more complex flows it becomes harder to find high-quality data from well controlled experiments that can provide well defined boundary conditions and detailed, high quality measurements in the turbulent region of interest.

Addressing the boundary condition issue first, one of the biggest needs is for experimental databases where the inflow turbulent state can be determined. As only one example, LES of jets including the nozzle geometry requires boundary conditions upstream of the nozzle exit, for which measurements are seldom made due to the difficulties in properly instrumenting the upstream location. For flows involving combustion, measurements of the inflow turbulent intensities, which can be much higher than for non-reacting external aerodynamic flows, are seldom made, but are critical to the fidelity of the simulation that can be expected.

For making measurements in the turbulent regions of interest, new diagnostic procedures such as Particle Image Velocimetry (PIV) are very promising in that they can give a much more detailed mapping of a turbulent flow than possible with other techniques, but it is not clear whether the accuracy and reproducibility is as good as for older methods such as hot-wire anemometry. For validation purposes then, the quality of turbulent statistics may be in question.

New experiments certainly would be valuable for validating LES methods that are in use today or are in development. In considering new experiments that would be helpful to those wishing to advance the utility of LES, our group came up with the following "wish list": (1) Consider geometries that have three-dimensional features but are not too complex, (2) Perform experiments at Reynolds numbers low enough to be tractable by LES at the same Reynolds number, (3) Attempt to minimize effects of blockage, interference, freestream turbulence, and to quantify these effects where they cannot be eliminated, (4) Make measurements of not only the mean flow but also the turbulent state at inflows.

\section{Recommended Practices and Key Considerations for LES}

This section outlines some recommended practices and other key considerations that should be kept in mind for performing LES. It is more a description of important items that need to be addressed, and not a comprehensive tutorial on specific procedures to be followed. While the previous section included discussion on hybrid RANS/LES, this section focuses on LES and does not consider strategies on how to treat the hybrid RANS/LES interface, which is a current area of significant research attention. 


\section{A. Spatial Resolution}

Adequate spatial resolution is a critical factor in the successful application of LES. For complex flows, the large-scale highly anisotropic turbulent features must be accurately captured, such that the subgrid modeling applies only to structures which lie in the inertial subrange or below. In this regard, a prominent issue is the resolution requirement in near-wall regions. Because these areas are dominated by small vortices which contain large amounts of turbulent energy, and thus lack scale separation, they are poorly suited to the description inherent in an LES approximation. As a result, resolution requirements near solid surfaces for LES are essentially the same as those for DNS.

It is generally recommended that LES be carried out using high-order (higher than second) or higher resolution numerical procedures. Although such techniques are more computationally expensive on a per point basis, because of their enhanced resolving power, far fewer grid points or spatial elements are required to achieve the same level of resolution as low-order methods. Thus, high-order techniques are usually more efficient for performing LES from a resource utilization perspective. While low-order schemes can and have been successfully employed for LES, it must be remembered that many grid points or spatial elements will be required when these methods are used.

Some attempt should be made made to identify the adequacy of spatial grid resolution. Due to the basic nature of LES, the standard concept of grid convergence in physical space is not applicable. However, comparisons with varying amounts of resolution can and should be made in frequency and wave number space. As the computational mesh is successively refined, more and more fine-scale turbulent structures are resolved, and the computation eventually transitions to a DNS. LES is typically performed at the limit of the computational resources available to any user for a particular problem. It is therefore unlikely that solutions on finer grids will be generated for comparative purposes. However, it is probably possible to obtain solutions on coarser grids. If a solution has been obtained on a baseline computational mesh, then a coarser grid constructed by removing every other mesh point in each coordinate direction, will result in a solution requiring only one-eighth of the resources (assuming the time step is held constant) as that of the baseline. We believe this is a result worth obtaining. The coarse mesh solution, however, should not be expected to compare extremely well with the baseline result. Differences in both time-mean and fluctuating quantities may not be small. The comparison can only indicate whether appreciable fluid phenomena are being captured correctly. Because the coarse mesh solution will only be able to resolve the largest structures, differences will be apparent. If the coarse mesh is so inadequate that it does not even provide indication of an under-resolved simulation, then it probably means that the baseline solution is unacceptable to be considered a legitimate LES.

Criteria often applied to indicate the adequacy of LES, are mesh spacings in wall units. Here we refer to wall-resolved LES only and not LES for where wall-layer models are used. Usual values are: ${ }^{43}$

$$
50 \leq \Delta x^{+} \leq 150, \Delta y_{\text {wall }}^{+}<1, \quad 15 \leq \Delta z^{+} \leq 40 \text { for LES }
$$

and for comparison

$$
10 \leq \Delta x^{+} \leq 20, \Delta y_{\text {wall }}^{+}<1, \quad 5 \leq \Delta z^{+} \leq 10 \text { for DNS. }
$$

These values are relevant for "flat-plate-like" configurations where the $x$ direction is streamwise, the $y$ direction is wall normal, and the $z$ direction is spanwise and homogeneous. Obviously, these definitions only apply for more academic, canonical flows. For practical problems, there may not be a homogeneous direction. If there is not a "flat-plate-like" region describing the inflow domain, it is unclear how to define a reference wall shear value in order to construct the wall units correctly. Persons generating the LES should do their best to define these quantities, and state the definitions clearly. Reference quantities will need to be based upon time-mean values in regions of fully-attached flow. It should also be noted that the above criterion are typically invoked without regard to the order of accuracy of the numerical method. For higher-order numerical schemes, a larger portion of the spatial wave number content can be captured with the same physical grid spacing as that employed when lower-order techniques are utilized. The above criterion will therefore be more conservative when higher-order techniques are applied.

Piomelli ${ }^{15}$ likes to define a mesh criteria based upon the number of grid points used to represent a distance equivalent to a boundary layer thickness. This would typically be about $20-40$ points. The criterion works well for simple flows. Where complex geometries contain bluff regions with separating shear layers and/or massive separation, the concept again becomes ambiguous. 


\section{B. Temporal Resolution}

The time step size needs to be chosen in order to correctly describe the important physical phenomena which are being simulated. As spatial resolution is increased by either a finer grid or higher fidelity spatial scheme, finer-scale turbulent structures are captured. For consistency, the time step must be adjusted in order to accommodate evolution and convection of these finer structures. DeBonis ${ }^{\mathbf{4 4}}$ showed the importance of considering not only the spatial order of accuracy but also the accuracy of the time-marching method. In particular, truncation error of a low-order time-stepping scheme may dominate that from the spatial scheme and remove any potential benefit from using a higher-order spatial discretization.

Obviously, smaller time steps are more desirable from an accuracy point of view, but also increase the resources required for a simulation. The proper compromise choice of a time step is not easy to obtain. Time resolution studies, while very useful, are not commonly performed for LES due to the computational expense. These might be carried out on coarser meshes, but because finer scale structures are not captured, the results may be misleading. Temporally higher-order numerical schemes might be employed. These are most often limited to explicit techniques, which cannot be applied efficiently for wall-bounded flows. Construction of turbulent frequency spectra may help indicate if important temporal phenomena are being properly resolved.

For certain academic canonical problems (e.g. turbulent channel flow) the $\Delta t^{+}<1$ criteria has been used, ${ }^{45}$ where $\Delta t^{+}=u_{\tau}^{2} \Delta t / \nu$ and $u_{\tau}$ is the friction velocity. Here $\Delta t^{+}=O(1)$ corresponds to the viscous time scale in the sublayer. Specific applications may also have their own time resolution requirements. Aeroacoustic applications for example, demand time steps capable of resolving wave propagation at acoustic frequencies. In this situation, the spatial grid resolution is also an important consideration. Because a high frequency sound wave will have a short wave length, the computational mesh must be sufficiently fine to support its transmission. An estimate of the frequencies that can be captured may be obtained from the speed of sound, the grid spacing, and properties of the numerical scheme in terms of the points per period of a periodic function that are supported at a given spatial wave number.

\section{Subgrid Modeling}

The basic foundation of LES is predicated upon intentionally leaving the finest-scale fluid structures underresolved. Thus, fewer computational resources are expended than those required for a DNS. Traditionally, the filtered Navier-Stokes equations are solved, giving rise to subgrid stresses which represent the effects of under-resolved structures, and which must be modeled in some fashion. It is commonly assumed that the fine-scale structures are relatively isotropic, so that simple subgrid models are generally utilized to account for their effects. The most common choice for this representation is in terms of an eddy viscosity, which requires specification of both a length and velocity scale, along with a Boussinesq stress/strain relationship. Perhaps the oldest of such models is that due to Smagorinsky, ${ }^{46}$ which is still frequently employed for performing LES. Its use is highly discouraged for a number of reasons. First, it tends to be overly dissipative. Second, the Smagorinsky eddy viscosity model constant has been accurately validated only for the simple flow of decaying turbulence. This same value for the model constant is often applied for more complex flows where it is not clear what the value should be. Third, the model does not allow the eddy viscosity to vanish in nearwall regions. As a result, a damping function is required in order to satisfy that condition. This is usually done in a somewhat ad hoc fashion. Near-wall behavior, and other deficiencies of the original Smagorinsky model have been overcome by more sophisticated approaches. Some popular LES methods include, but are not limited to, the following: 1) two-point closures, ${ }^{47}$ 2) scale-similar and mixed models ${ }^{48,49} 3$ ) structure function models, ${ }^{50,51} 4$ ) dynamic model approaches, ${ }^{52-55} 5$ ) deconvolution techniques, ${ }^{56,57}$ and 6) truncated Navier-Stokes treatments. ${ }^{58,59}$

The alternative to traditional subgrid methodology now known as ILES relies upon features of the numerical scheme to supply dissipation of turbulent energy, which is lost because the finest-scale structures are not being resolved. The first attempt at such a technique was embodied in the MILES ${ }^{5,60}$ approach. This method was based upon upwind numerical schemes with monotonicity-preserving behavior.

The specific term Implicit Large-Eddy Simulation (ILES) was originally used by Visbal, ${ }^{61,62}$ to describe a specific method which utilized both implicit high-order central-finite-differencing and filtering schemes. It was shown that dissipation was being added only in the high spatial wave number regime, where the solution began to exhibit a lack of resolution. Details of the evolution of ILES as an overall approach are discussed in Refs. 63 and 64. More recently, the term "ILES" is being applied to any approach which relies upon the numerical method to supply dissipation, in lieu of an explicitly added subgrid model. The potential danger is 
in not knowing how the numerical scheme is resolving structures, particularly those near the presumed cut-off scale. Some evidence of successful application of a particular method should be provided to add credibility to the method. Examples of such successful applications are provided in Refs. 28-30. Grinstein and Fureby ${ }^{22}$ have used Modified Equation Analysis (MEA) to examine the effects of various flux limiting schemes and their relation to the built-in (or implicit) subgrid model in ILES. They found that a key component to the dissipative nature is the use of upwind biased flux reconstruction, providing virtually all of the implicit dissipation.

In contrast to carefully formulated ILES techniques such as these examples, low-order methods utilizing coarse computational meshes at high Reynolds numbers, are probably not capturing many fine structures. For these situations, the dissipation provided by the numerical method might well exceed that of explicitly added subgrid models.

As described previously, it is generally not possible to separate the dissipation associated with a particular numerical scheme, from that inherent in a subgrid model. In computations where explicitly added subgrid models are utilized, companion simulations without the use of models should also be performed. This will allow effects of the numerical method alone to be assessed, and contributions of the model to be evaluated.

Because of requirements in near-wall regions noted previously, an attractive approach for simulating high-Reynolds number flows is the use of wall-layer models. With this technique, only structures in regions away from solid surfaces are resolved, while those in near-wall regions are modeled. An overview of this methodology and discussion of critical issues is given by Piomelli. ${ }^{15}$

\section{Inflow Conditions}

Any complete LES must account for fine-scale structures at the inflow region of the computational domain, if this region is turbulent. It is noted that some simulations may be transitional, where the inflow is not fully turbulent. In other situations, particularly those with fixed separation locations as for cavities and bluff bodies, the small-scale unsteady structures in the attached upstream flow may have a minimal effect on the downstream wakes and shear layers. This is because once separation occurs, the subsequent inherently unstable flow has a natural tendency to break down and form small fluid structures. Neglecting fine-scale structures at the inflow however, always poses a risk of missing some essential physical processes. Several ways exist to generate turbulent inflow conditions. None of them are trivial to carry out, and all of them have limitations, approximations, and/or assumptions associated with them. Some of the popular methods for generating turbulent inflow conditions include, but are not limited to the following:

\section{The Recycling/Rescaling Technique}

The concept of recycling/rescaling was first introduced by Spalart, ${ }^{65}$ simplified for incompressible flows by Lund et al.. ${ }^{66}$ and extended to compressible applications by Sagaut et al. ${ }^{67}$ The technique is implemented by extracting profiles of dependent variables at some location downstream of the inflow boundary, rescaling them, and then reintroducing at the inflow plane, in a dynamic fashion. Typically, the flow between the recycled boundaries must initially be artificially perturbed in order to generate fine-scale structures. Eventually, it will then achieve an equilibrium state. The advantage of this method is that the inflow is treated implicitly as part of the overall simulation. One disadvantage is that the rescaling is approximate. In addition, there is an imposed frequency determined by the spatial distance between the recycling boundaries. Having a greater distance between the boundaries reduces the frequency, and helps de-correlate the solution between the two. Unfortunately, this greater distance adds to the computational expense.

\section{Introducing Artificial Perturbations About the Mean Flow}

Some form of unsteady disturbances may be superimposed upon assumed steady profiles at the inflow boundary. These disturbances can be specified from analytic representations or obtained from some other means. This method is sometimes referred to as synthetic turbulence, and successful simulations have been carried out using perturbations based upon Fourier series or other analytically-generated disturbances. ${ }^{37,68-70}$ When such techniques are employed, the flow generally attains its own equilibrium state somewhat downstream of the inflow. The computational domain needs to be constructed in order to allow this to happen. The disturbances need to lie in a realistic range of acceptable values. If they are too small, turbulence will not be generated or supported. If they are too large, unphysical behavior may result. Guidance about reasonable 
magnitudes of disturbances might be provided by previous simulations, if available for any specific application. In general, these magnitudes will be ambiguous, and the quality of the solution can only be judged after transition to turbulence has been generated.

\section{Complete Time-Varying Inflow Profiles}

Time-accurate inflow profiles may be obtained from an initial separate or auxiliary simulation, and cycled into the inflow boundary. If this technique is utilized, correct specification of subsonic/supersonic inflow conditions must not be violated. For subsonic compressible flows, disturbances created by inflow specification must be allowed to propagate upstream, out of the computational domain. Ways of obtaining the profiles are not unique. Individual profiles which are cycled into the inflow boundary, must correspond to the time step utilized for the computation.

A dedicated auxiliary simulation appears to have been first utilized by Akselvoll and Moin, ${ }^{71,72}$ where an inflow computation was run simultaneously in conjunction with the primary simulation. An alternate approach, employed by Adams ${ }^{73,74}$ and Rizzetta, ${ }^{75-77}$ is to obtain a time-accurate sequence of profiles, and then make the sequence periodic in time. The advantage of this technique is that the simulation can proceed indefinitely, where the inflow profiles are continuously cycled into the computational domain. Care must be taken that the imposed frequency for the period of the time sequence does not adversely affect the solution. Methods for making the profiles periodic are problematic. Typically, a large file of the temporally accurate inflow information needs to be created. There might be a savings in computational resources which is derived by making the inflow profiles periodic, but this comes at the expense of creating a pseudo-periodic flow. This, and other methods of specifying information at the inflow boundary (e.g. adding unsteady disturbances), usually produces some anomalies at the inflow plane. It must be established that such anomalies are not severe enough to destroy the integrity of the simulation.

\section{Perturbing/Tripping the Inflow Region}

As an alternative to the aforementioned techniques, the inflow region may be perturbed in order to generate fine-scale structures. Because the inflow is typically a "stable" region, it is highly unlikely that small structures will arise naturally in any simulation. Perturbations have been generated for example, using a blowing/suction wall boundary condition by Rai ${ }^{78}$ and Fasel, ${ }^{79}$ which may generate bypass transition. Therefore, the inflow region needs to be sufficiently long for equilibrium flow to spatially evolve. An alternate technique employs a body force added to the Navier-Stokes equations, and provides a tripping mechanism. This approach can represent a plasma actuator, and has been utilized by Visbal et al. ${ }^{80}$ and by Rizzetta and Visbal. ${ }^{81}$ The technique is less likely to create any problems at the inflow boundary, but the entire computational domain must include the perturbing region and the distance required to attain equilibrium flow. However the inflow is developed, there is usually some criteria to be met upstream of the actual region of interest in the simulation. Often, this is a boundary layer thickness or profile ahead of some geometric feature. If profile or other information is available for comparison, as for example from experimental measurements, then these comparisons should be made. In any event, profile information should be shown. Comparisons in wall units $\left(u^{+}\right.$vs $\left.y^{+}\right)$can be made to the universal logarithmic profile. Time-mean fluctuating quantities $\left(\overline{u^{\prime} v^{\prime}}, \overline{u^{\prime} u^{\prime}}, \overline{v^{\prime} v^{\prime}}, \overline{w^{\prime} w^{\prime}}\right.$, etc.) can also be shown for the equilibrium inflow region. This will provide some indication that the inflow is being correctly described, and corresponds to the criteria that one wishes to match.

\section{E. Outflow and Lateral Boundaries}

Care must be taken to preclude spurious numerical reflections from computational boundaries. This is a particularly important consideration for the outflow boundary in subsonic flows as well as aeroacoustic and reacting flow problems. Various techniques are typically employed for the treatment of outflow boundaries. One set of boundary conditions is written to eliminate these reflections using characteristic wave relations. ${ }^{82-85}$ Another set of boundary conditions uses the more ad hoc approach referred to as absorbing layers/sponge regions/exit zone ${ }^{86}$ where gradually increased grid spacing combined with dissipation of the numerical scheme serves to damp waves as they near the boundary. Additional dissipation or source terms in the governing equations are sometimes added to increase the damping. This precludes capturing of fine-scale 
fluid structures, destroying some features which may otherwise result in reflections. One must also ensure that reflections do not occur at lateral boundaries, or that information does not fictitiously accumulate there.

If there is a geometrically homogeneous direction inherent in the simulation, periodic conditions are commonly employed at the boundaries in that direction. In this case, care must be taken such that the extent of the computational domain is sufficiently large so as not to impose an artificial constraint on the formation of fluid structures in the periodic direction. Examining domains with variations in the outflow boundary location and width of the periodic direction can indicate if reflections are a problem or if the width is sufficient, although this increases the resources required for the simulations. Proper extent of the lateral domain may be determined from two-point auto-correlations, using differing amounts of spacing in the homogeneous direction. The lateral extent needs to be sufficiently large such that the two-point statistics are de-correlated over a length equal to one-half of the expanse. Some experimental correlations are available to use as a guide, but these are mostly for supersonic flows.

For combustion LES, additional complexities arise since a flame may be severely affected by the acoustics of the combustion chamber, and therefore of the acoustic impedance of the outflow boundary. It is usually very difficult to represent the true impedance conditions of a laboratory or real combustor in a simulation without including an unrealistically large part of the combustor. Instead, the impedance of the outflow can be varied to quantify the importance of the outflow boundary.

\section{F. Methods of Collecting Statistical Information}

It is always useful to save statistical information from any LES. This will not only confirm that some finescale structures are in fact being captured, but can also provide insight into some of the physical processes occurring in the flow. Both temporal frequency and spatial wave number spectra should be obtained. This is not an easy task to accomplish, as much information is involved. There are several ways in which the required data can be collected. Some practitioners of LES like to periodically record complete data sets of the entire instantaneous three-dimensional flowfield. This allows post processing in order to obtain statistical information, and the construction of ensemble averages. Care must be taken that enough samples have been recorded in order to produce statistically meaningful averages. Because of that requirement, a vast quantity of information must be saved. This may put a large burden upon the amount of space available for storing such information. Post processing can also be time consuming. The advantage of this approach is that almost any correlation or quantity (with the possible exception of frequency spectra) can be obtained after the simulation has been completed. It is something of a brute force method, but allows extraction of information which had not been anticipated prior to beginning the simulation.

An alternate technique is to save time-mean values only of selected variables. For example, if $\bar{u}$ and $\overline{u^{2}}$ are obtained, then $\overline{u^{\prime} u^{\prime}}$ can be generated following the Reynolds decomposition as $\overline{u^{\prime} u^{\prime}}=\overline{u^{2}}-\bar{u}^{2}$. This requires knowing which variables to save prior to beginning the computation. For each quantity, a time-mean "running" average may be computed, so that at any point in time, mean quantities are available. Not only does this minimize the amount information to be generated, but also allows the simulation to be restarted and continued further at any point.

At specific isolated locations in the flowfield, it is also useful to record complete time histories of selected variables. These locations may be entire lines in one or more computational coordinate directions, particularly if those directions are geometrically homogeneous. Data of this nature will permit the calculation of temporal frequency spectra of particular quantities, as well as wave number spectra along the direction of the line of the recorded information. As noted above, the variables to be recorded and their locations, must be selected prior to beginning the simulation.

\section{G. Initial Transients and Statistical Data}

Starting from any initial state, solutions must be evolved for a sufficiently long period so that transients are purged from the computational flowfield, and an equilibrium turbulent state is achieved. This can be a long process, particularly for low Mach number flows. If the transients have not been entirely removed, then temporal averages and statistical quantities may be corrupted. It is a difficult task to determine exactly when the transients have been eliminated. Evolving the solution extensively in time will mitigate the effect of initial transients, but will result in utilization of more computing resources. If it is possible to initialize the flowfield with a solution obtained from the RANS equations, that might reduce the overall computing time. 
Once equilibrium has been attained, processing should continue for a sufficient period in order to ensure that meaningful statistical information has been collected. This can be established by periodically monitoring the evolution of statistical data. For example, the solution can be processed for a time period equal to $T$, and statistical information can be extracted. The solution may then be further processed to $2 T$, statistics computed again, and compared to the prior ones. The procedure can be repeated until statistical information has temporally converged. In this regard, mean values of primitive variables such as $\bar{u}, \bar{v}, \ldots$ etc. converge quite rapidly whereas mean values of fluctuating quantities such as $\overline{u^{\prime} u^{\prime}}, \overline{v^{\prime} v^{\prime}}, \ldots$ etc. converge less rapidly and subsequently require both longer sampling times and more careful monitoring.

\section{H. Validation}

It is a good idea to have validated use of a particular code, and experience of the user, on some canonical problems prior to embarking on a new simulation. This will establish confidence in the approach, as well as in the user, to carry out a meaningful LES. Some typical canonical problems which have been used for validation of LES include decaying homogeneous isotropic turbulence, turbulent channel flows (at Reynolds numbers that are accessible to particular individuals via available computing resources), flat-plate boundary layers, and circular cylinders at low Reynolds numbers. For all of these examples, previous computations (some DNS) and/or experimental data are available for comparison and validation. As mentioned previously, organizations such as the European Research Community on Flow, Turbulence, and Combustion (ERCOFTAC) have assembled extensive validation databases for turbulent flows.

\section{Shock Waves}

Flows containing shock waves of appreciable strength have certain demanding requirements. The challenge in such simulations is to capture the shock in a stable and accurate manner, and also provide the spatial accuracy required to simulate some of the fine-scale structures inherent in turbulence. Shock waves are most commonly treated by low-order methods, often employing upwind schemes. These approaches are frequently not sufficiently accurate to provide LES resolution. Higher-order upwind and/or hybrid approaches are alternative techniques. Garnier et $\mathrm{al}^{87}$ examined the capability of a number of shock-capturing schemes to be applied to LES. There have been significant efforts to employ weighted essentially non-oscillatory (WENO) methods, ${ }^{88,89}$ particularly within hybrid approaches, to provide shock-capturing where needed, but then eliminate dissipation in turbulent regions away from shocks. Adaptive shock filters, such as that of Visbal and Gaitonde ${ }^{90}$ also have been explored where a high-order spatial discretization is used in conjunction with a reduced-order filter applied only near shock waves. Optimal tailoring of numerical schemes for LES of flows containing shock waves remains an area of ongoing research.

\section{J. Chemically Reacting Flows}

It is beyond the scope of this paper to address the situation of chemically reacting flows completely. As a result, we only give a very brief overview. Two recent papers providing extensive details of currently used practices for chemically reacting flows are by Fureby ${ }^{9}$ and Pitsch. ${ }^{17}$

Reacting flows are usually described by the compressible Navier Stokes equations supplemented by transport equations for the species concentrations. The species transport equations are connected by a reaction network, $\left[P_{i j}\right]\left\{\mathfrak{T}_{i}\right\}=\{0\}$, where $P_{i j}$ is the stoichiometric matrix and $\mathfrak{T}_{i}$ is the vector of species with concentrations $Y_{i}$, describing how (cold) reactants form (hot) products at a rate usually described by an Arrhenius expression. Since the chemical reactions occur on very small scales (on the order of the Taylor scales or smaller), most of the combustion chemistry is subgrid, and models needs to be developed for either the tracking of the flame, being considered as thin in comparison to the LES grid, or the subgrid turbulence chemistry interactions, taking place within the smallest resolved scales and the subgrid scales. Broadly speaking we differentiate between two types of models: flamelet models and finite rate chemistry models, both of which may be further subdivided into several classes of models depending on the assumptions involved in the formulations and modeling.

In flamelet models the flame is considered thin compared to the length scales of the flow, and the flame is thus an interface between fuel and oxidizer (for non-premixed combustion) or between reactants and products (for premixed combustion). Due to the scale separation it is convenient to decouple the simulation of the flow and interface from that of the chemical kinetics, which can be modeled by the laminar flame speed, $s_{L}$, 
and by mapping the structure of a one-dimensional laminar flame onto the normal of the interface closure is achieved. A mixture fraction, $\tilde{z}$, is most often used for non-premixed flames and a progress variable, $\tilde{c}$, or a kinematic $G$ field is usually used for premixed flames, whereas for stratified combustion both $\tilde{c}$ (or $G$ ) and $\tilde{z}$ are required. For further details concerning the these models, we refer to Refs. 91 and 92 . Flamelet models generally have the advantage of being less computationally expensive than finite rate chemistry models, but both methods require closure modeling, to which the results can be rather sensitive.

In finite rate chemistry models an attempt is made to model the filtered reaction rates, i.e. to take into account the subgrid turbulence chemistry interactions. This poses a modeling challenge even greater than that of developing reliable subgrid closure models due to the complexity of these interactions, and the number of species taking place in the reaction mechanism of most practical fuels. The first step in this type of modeling is to develop reduced (or global) reaction mechanisms, capable of preserving at least the laminar flame speed, $s_{L}$, and the heat release, $Q$, over a range of equivalence ratios. This is a research area on its own and recently considerable progress has been made, e.g. Refs. 93 and 94 . The second step is to model the turbulence chemistry interactions, which may be substantial as the reaction rates usually depend bi-linearly on the concentrations and exponentially on the temperature, so that small turbulent fluctuations in the flow may create large fluctuations in the reaction rates. Although a closed formulation of the filtered reaction rates can be obtained using Probability Density Functions (PDF), ${ }^{95}$ the specification of the PDF is difficult. Either Monte-Carlo methods ${ }^{96}$ or presumed PDF methods ${ }^{97}$ are necessary, with the former currently being computationally expensive and the latter much simpler but empirical. The use of PDF methods in LES is typically referred to as Filtered Density Functions (FDF) as originally described by $\mathrm{Givi}^{96,98}$ and Pope. ${ }^{99}$ While research into developing FDF approaches continues, semi-empirical methods such as the Partially Stirred Reactor (PaSR) model, the Eddy Dissipation Concept (EDC), ${ }^{19,100}$ and references therein, or the Thickened Flame Model (TFM) ${ }^{101}$ are often used. Another very interesting and promising approach is the Linear Eddy Model, ${ }^{102}$ in which simplified one-dimensional equations are solved on embedded grids, thus alleviating the need for the turbulence chemistry interaction modeling, but at the expense of higher computational cost and other simplifications.

As demonstrated in Refs. 9,17,18 as well as in references therein, both flamelet and finite rate chemistry LES are quite successful in predicting reacting flows in both laboratory combustors and in more complicated reacting flow systems. This depends primarily on the fact that the large-scale flow is resolved, thereby better representing the macroscopic mixing essential to the reaction process. Due to the fact that the Reynolds number often is lower in a combustor than in many other (external flow) applications, thus providing a better resolved flow, it is anticipated that the use of LES in combustion will provide a useful tool not only to the academia but also to industry, when evaluating concepts and addressing key operational issues.

\section{Future Research Directions}

In the future, LES is likely to become used for a broader range of flow problems and for more complex problems including more multi-disciplinary applications. Throughout the previous sections of this paper, several areas of LES that require further work to advance the method as a reliable approach to calculating turbulent flows were identified. To conclude this paper, we briefly summarize these areas.

The broad topic of how to account for the subgrid scales includes many areas of active research which should continue. Performing LES through boundary layers in flows of appreciable Reynolds number down to the wall remains largely prohibitive. As a result, further development of wall-layer models is warranted. In the area of hybrid RANS/LES, some newer approaches that recognize the importance of treating the interface region carefully, such as those which are investigating ways to introduce disturbances into the LES region likely offer a better chance of success than continuous hybrid RANS/LES which simply allow the eddy viscosity to be some ad-hoc curve-fitted function between the RANS and LES limits. These newer hybrid RANS/LES techniques which consider the importance of the interface regions should continue to be explored.

The ILES community has made a strong case for the applicability of ILES to many flows for which implicit subgrid modeling works at least as well as using explicit subgrid models. As the popularity of ILES grows, the experts in this area should attempt to recommend flows for which ILES may be appropriate and those for which explicit subgrid modeling is still a better choice. They should continue to emphasize that not all numerical schemes are appropriate for ILES (as is true for all LES) and provide sufficient recommendations on the best choices in numerical schemes for non-experts considering the approach. 
The inadequacy of RANS for reacting flow simulations ranging from low speed combustors to supersonic combustion ramjets (scramjets) has pointed to LES as the logical technique to improve solution accuracy. While the use of explicit versus implicit subgrid modeling remains an area of open debate for some classes of flows, advances in subgrid modeling for reacting flow simulations is necessary.

Importance of boundary conditions, and in particular inflow boundary conditions, should be emphasized. It is quite challenging to set inflow boundary conditions in an LES that accurately represent the turbulent inflow state. There are several techniques which are currently in use or under investigation, and more experience with these techniques is needed to identify the benefits and limitations of each. Experiments that quantify the inflow turbulent state in detail are highly desirable for LES validation and further boundary condition development.

There are many areas related to computational grids for which work would help extend the applicability and reliability of LES. The utility of using unstructured grid methods for complicated flow geometries has been demonstrated for inviscid and RANS CFD. Continued work in higher-order unstructured methods is needed to remove the speculation that commonly available low-order unstructured grid methods are too dissipative for LES. The discontinuous Galerkin approach in particular looks attractive for application to LES. Even for structured grids, guidelines for construction of grids appropriate for use with LES (which likely are very different than what would have been used for RANS) are necessary.

Calculation of flows involving shock waves in an area for which work in numerical schemes is still needed. The challenge is maintaining spatial accuracy to simulate turbulence without degrading stability near shocks. Higher-order upwind methods and hybrid central/upwinded techniques have been investigated in recent years and should continue to be explored.

Finally, to preserve trust in LES as having the potential to improve the aerospace and fluid dynamic communities' capabilities to compute turbulent flows, and not lead to LES being considered the latest overhyped method, we should expect studies to consider and diligently report the key assumptions used in a particular analysis. A simulation for which no attention to modeling sensitivities was considered, yet fortuitously matches one set of experimental data, should not be considered a satisfactory LES. Reports of calculations using LES should show sensitivity to modeling factors such as grid density, grid stretching, time discretization, subgrid modeling, boundary conditions, and other factors. It should be expected that examination of these modeling parameters be performed for any LES, with an identification of potential sources of errors and an estimation of the error bounds.

\section{References}

\footnotetext{
${ }^{1}$ Moin, P. F. and Kim, J., "Tackling Turbulence with Supercomputers," Scientific American, Vol. 276, No. 1, Jan. 1997, pp. $62-68$.

${ }^{2}$ Lesieur, M. and Metais, O., "New Trends in Large-Eddy Simulations of Turbulence," Annual Review of Fluid Mechanics, Vol. 28, Dec. 1996, pp. 45-82.

${ }^{3}$ Pope, S. B., "Ten Questions Concerning the Large Eddy Simulation of Turbulent Flows," New Journal of Physics, Vol. 4, No. 35, Mar. 2004, pp. 1-24.

${ }^{4}$ Boris, J. P., "On Large Eddy Simulation Using Subgrid Turbulence Models," Whither Turbulence? Turbulence at the Crossroads, edited by J. Lumley, Springer-Verlag, New York, NY, 1990, pp. 344-353.

${ }^{5}$ Boris, J. P., Grinstein, F. F., Oran, E. S., and Kolbe, R. J., "New Insights into Large Eddy Simulation," Fluid Dynamics Research, Vol. 10, No. 4-6, Dec. 1992, pp. 199-228.

${ }^{6}$ Reynolds, W. C., "The Potential and Limitations of Direct and Large Eddy Simulations," Whither Turbulence? Turbulence at the Crossroads, edited by J. Lumley, Springer-Verlag, New York, NY, 1990, pp. 313-343.

${ }^{7}$ Spalart, P. R., "Strategies for Turbulence Modeling and Simulations," International Journal of Heat Fluid Flow, Vol. 21, No. 3, 2000, pp. 252-263.

${ }^{8}$ Spalart, P. R., "Trends in Turbulence Treatments," AIAA Paper 2000-2306, Jun. 2000.

${ }^{9}$ Fureby, C., "Toward the Use of Large Eddy Simulation in Engineering," Progress in Aerospace Sciences, Vol. 44, No. 6, Aug. 2008, pp. 381-396.
} 
${ }^{10}$ Rizzetta, D. P., Visbal, M. R., and Morgan, P. E., "A High-Order Compact Finite Difference Scheme for Large-Eddy Simulation of Active Flow Control," Progress in Aerospace Sciences, Vol. 44, No. 6, Aug. 2008, pp. 397-426.

${ }^{11}$ Tucker, P., "The LES Model's Role in Jet Noise," Progress in Aerospace Sciences, Vol. 44, No. 6, Aug. 2008 , pp. $427-436$.

${ }^{12}$ Georgiadis, N. J. and DeBonis, J. R., "Navier-Stokes Analysis Methods for Turbulent Jet Flows with Application to Aircraft Exhaust Nozzles," Progress in Aerospace Sciences, Vol. 42, No. 5, Jul. 2006, pp. 377-418.

${ }^{13}$ Bodony, D. J. and Lele, S. K., "On Using Large-Eddy Simulation for the Prediction of Noise from Cold and Heated Turbulent Jets," Physics of Fluids, Vol. 17, No. 085103, 2006, pp. 1-20.

${ }^{14}$ DeBonis, J. R., "Progress Toward Large-Eddy Simulations for Prediction of Realistic Nozzle Systems," Journal of Propulsion and Power, Vol. 23, No. 5, Sep. 2007, pp. 971-980.

${ }^{15}$ Piomelli, U., "Wall-Layer Models for Large-Eddy Simulations," Progress in Aerospace Sciences, Vol. 44, No. 6, Aug. 2008, pp. 437-446.

${ }^{16}$ Edwards, J. R., "Numerical Simulations of Shock/Boundary Layer Interactions Using Time-Dependent Modeling Techniques: A Survey of Recent Results," Progress in Aerospace Sciences, Vol. 44, No. 6, Aug. 2008, pp. 447-465.

${ }^{17}$ Pitsch, H., Desjardins, O., Balarac, G., and Ihme, M., "Large Eddy Simulation of Turbulent Reacting Flow," Progress in Aerospace Sciences, Vol. 44, No. 6, Aug. 2008, pp. 466-478.

${ }^{18}$ Fureby, C., "LES Modeling of Combustion for Propulsion Applications," Proceedings of the Royal Society A, To appear 2009.

${ }^{19}$ Berglund, M., Fureby, C., Sabel'nikov, V., and Tegner, J., "On the Influence of Finite Rate Chemistry in LES of Self-Ignition in Hot Confined Supersonic Airflow," European Space Agency Special Report ESA SP-659, 2008.

${ }^{20}$ Spalart, P. R., "Young-Person's Guide to Detached Eddy Simulation Grids," NASA CR 2001-211032, Jul. 2001.

${ }^{21}$ Drikakis, D., Hahn, M., Grinstein, F., DeVore, C., Fureby, C., Liefendahl, M., and Youngs, D., "Limiting Algorithms," Implicit Large Eddy Simulation, edited by F. F. Grinstein, L. G. Margolin, and W. J. Rider, Cambridge University Press, New York, NY, 2007, pp. 94-129.

${ }^{22}$ Grinstein, F. F. and Fureby, C., "On Flux-Limiting-Based Implicit Large Eddy Simulation," Journal of Fluids Engineering, Vol. 129, No. 12, Dec. 2007, pp. 1483-1492.

${ }^{23}$ Yee, H. C., Sandham, N. D., and Djomehri, M. J., "Low-Dissipative High-Order Shock-Capturing Methods Using Characteristic-Based Filters," Journal of Computational Physics, Vol. 150, 1999, pp. 199-238.

${ }^{24}$ Mavripilis, D. J., Pelaez, J., and Kandil, O., "Large Eddy and Detached Eddy Simulations Using an Unstructured Multigrid Solver," Proceedings of the 3rd AFOSR International Conference on DNS/LES, edited by C. Liu, L. Akell, and T. Beutner, Aug. 2001.

${ }^{25}$ Forsythe, J. R., Squires, K. D., Wurtzler, K. E., and Spalart, P. R., "Detached-Eddy Simulation of Fighter Aircraft at High-Alpha," Journal of Aircraft, Vol. 41, No. 2, 2004, pp. 193-200.

${ }^{26}$ Zang, Z. J., "Spectral (Finite) Volume Method for Conservation Laws on Unstructured Grids: Basic Formulation," Journal of Computational Physics, Vol. 178, No. 1, 2002, pp. 210-251.

${ }^{27}$ Nastase, C. R. and Mavripilis, D. J., "High-Order Discontinuous Galerkin Methods Using an hp-Multigrid Approach," Journal of Computational Physics, Vol. 213, No. 1, 2006, pp. 330-357.

${ }^{28}$ Grinstein, F. F., "Vortex Dynamics and Transition to Turbulence in Free Shear Flows," Implicit Large Eddy Simulation, edited by F. F. Grinstein, L. G. Margolin, and W. J. Rider, Cambridge University Press, New York, NY, 2007, pp. 265-291.

${ }^{29}$ Fureby, C., Liefendahl, M., U., S., L., P., and Persson, T., "Incompressible Wall-Bounded Flows," Implicit Large Eddy Simulation, edited by F. F. Grinstein, L. G. Margolin, and W. J. Rider, Cambridge University Press, New York, NY, 2007, pp. 301-328.

${ }^{30}$ Fureby, C., Knight, D. D., and Kupiainen, M., "Compressible Turbulent Shear Flows," Implicit Large Eddy Simulation, edited by F. F. Grinstein, L. G. Margolin, and W. J. Rider, Cambridge University Press, New York, NY, 2007, pp. 329-369.

${ }^{31}$ Leschziner, M. A., "Simulating Flow Separation from Continuous Surfaces: Routes to Overcoming the Reynolds Number Barrier," Proceedings of the Royal Society A, To appear 2009.

${ }^{32}$ Spalart, P. R., Jou, W. H., Strelets, M., and Allmaras, S. R., "Comments on the Feasibility of LES for Wings, and on a Hybrid RANS/LES Approach," Proceedings of the 1st AFOSR International Conference on DNS/LES, edited by C. Liu and Z. Liu, Greyden Press, Columbus, OH, Aug. 1997.

${ }^{33}$ Spalart, P. R., Deck, S., Shur, M. L., Squires, K. D., Strelets, M. K., and Travin, A., "A New Version of Detached-Eddy Simulation, Resistant to Ambiguous Grid Densities," Journal of Theoretical and Computational Fluid Dynamics, Vol. 20, No. 3, July 2006, pp. 181-195.

${ }^{34}$ Speziale, C. G., "Turbulence Modeling for Time-Dependent RANS and VLES: A Review," AIAA Journal, Vol. 36, No. 2, Mar. 1998, pp. 173-184.

${ }^{35}$ Girimaji, S. S., "Partially-Averaged Navier-Stokes Model for Turbulence: A Reynolds-Averaged Navier-Stokes to Direct Numerical Simulation Bridging Method," Journal of Applied Mechanics, Vol. 73, No. 3, 2006, pp. 413-421.

${ }^{36}$ Shih, T. H., Liu, N. S., and Chen, C. L., "A Strategy for Very Large Eddy Simulation of Complex Turbulent Flow," AIAA Paper 2006-0175, Jan. 2006.

${ }^{37}$ Batten, P., Goldberg, U., and Chakarvarthy, S., "Interfacing Statistical Turbulence Closures with Large-Eddy Simulation," AIAA Journal, Vol. 42, No. 3, Mar. 2004, pp. 485-492.

${ }^{38}$ Davidson, L. and Dahlstrom, S., "Hybrid LES-RANS: An Approach to Make LES Applicable at High Reynolds Number," International Journal of Computational Fluid Dynamics, Vol. 19, No. 4, Aug. 2005, pp. 415-427.

${ }^{39}$ Piomelli, U., Balaras, E., Pasinato, H., Squires, K. D., and Spalart, P. R., "The Inner-Outer Layer Interface in LargeEddy Simulations with Wall-Layer Models," International Journal of Heat and Fluid Flow, Vol. 24, No. 4, 2005 , pp. 538-550.

${ }^{40}$ Piomelli, U., Radhakrishnan, S., and De Prisco, G., "Turbulent Eddies in the RANS/LES Transition Region," Advances in Hybrid RANS-LES Modelling, edited by S. Peng and W. Haase, Springer-Verlag, Berlin, Heidelberg, 1993, pp. 21-36.

${ }^{41}$ Abe, K., "A Hybrid LES/RANS Approach Using an Anisotropy-Resolving Algebraic Turbulence Model," International Journal of Heat and Fluid Flow, Vol. 26, No. 2, April 2005, pp. 204-222. 
${ }^{42}$ Uribe, J., Jarrin, N., Prosser, R., and Laurence, D., "Hybrid v2f RANS/LES Model and Synthetic Inlet Turbulence Applied to a Trailing Edge Flow," Proceedings of the 5th International Symposium on Turbulence and Shear Flow Phenomena, Munich, Germany, 2007, pp. 701-706.

${ }^{43}$ Piomelli, U. and Balaras, E., "Wall-Layer Models for Large-Eddy Simulations," Annual Review of Fluid Mechanics, Vol. 34, Jan. 2002, pp. 349-374.

${ }^{44}$ DeBonis, J. R. and Scott, J. N., "Study of the Error and Efficiency of Numerical Schemes for Computational Aeroacoustics," AIAA Journal, Vol. 40, No. 2, Feb. 2002, pp. 227-234.

${ }^{45}$ Choi, H. and Moin, P., "Effects of the Computational Time Step on Numerical Solutions of Turbulent Flow," Journal of Computational Physics, Vol. 113, No. 1, Jul. 1994, pp. 1-4.

${ }^{46}$ Smagorinsky, J. S., "General Circulation Experiments with the Primitive Equations," Monthy Weather Review, Vol. 91, No. 3, Mar. 1963, pp. 99-165.

${ }^{47}$ Chollet, J.-P. and Lesieur, M., "Parameterization of Small Scales of Three-Dimensional Isotropic Turbulence Utilizing Spectral Closures," Journal of the Atmospheric Sciences, Vol. 38, No. 12, Dec. 1981, pp. 2747-2757.

${ }^{48}$ Bardina, J., Ferziger, J. H., and Reynolds, W. C., "Improved Subgrid-Scale Models for Large-Eddy Simulation," AIAA Paper 1980-1356, Jul. 1980.

${ }^{49}$ Zang, Y., Street, R. L., and Koseff, J. R., "A Dynamic Mixed Subgrid-Scale Model and its Application to Turbulent Recirculating Flows," Physics of Fluids A, Vol. 5, No. 12, Dec. 1993, pp. 3186-3196.

${ }^{50}$ Metais, O. and Lesieur, M., "Spectral Large-Eddy Simulation of Isotropic and Stably Stratified Turbulence," Journal of Fluid Mechanics, Vol. 239, Jun. 1992, pp. 157-194.

${ }^{51}$ Ducros, F., Comte, P., and Lesieur, M., "Large-Eddy Simulation of Transition to Turbulence in a Boundary Layer Developing Spatially over a Flat Plate," Journal of Fluid Mechanics, Vol. 326, Nov. 1996, pp. 1-36.

${ }^{52}$ Germano, M., Piomelli, U., Moin, P., and Cabot, W. H., "A Dynamic Subgrid Scale Eddy Viscosity Model," Physics of Fluids A, Vol. 3, No. 7, Jul. 1991, pp. 1760-1765.

${ }^{53}$ Lilly, D. K., "A Proposed Modification of the Germano Subgrid-Scale Closure Method," Physics of Fluids A, Vol. 3, No. 3, Mar. 1992 , pp. $633-635$.

${ }^{54}$ Ghosal, S., Lund, T. S., Moin, P., and Akselvoll, K., "A Dynamic Localization Model for Large-Eddy Simulation of Turbulent Flows," Journal of Fluid Mechanics, Vol. 286, Mar. 1995, pp. 229-255.

${ }^{55}$ Meneveau, C., Lund, T. S., and Cabot, W. H., "A Lagrangian Dynamic Subgrid-Scale Model of Turbulence," Journal of Fluid Mechanics, Vol. 319, Jul. 1996, pp. 353-385.

${ }^{56}$ Stoltz, S. and Adams, N. A., "An Approximate Deconvolution Procedure for Large-Eddy Simulation," Physics of Fluids, Vol. 11, No. 7, Jul. 1999, pp. 1699-1701.

${ }^{57}$ Stoltz, S., Adams, N. A., and Kleiser, L., "The Approximate Deconvolution Model for LES of Compressible Flows and Its Application to Shock-Turbulent-Boundary-Layer Interaction," Physics of Fluids, Vol. 13, No. 10, Oct. 2001 , pp. $2985-3001$.

${ }^{58}$ Domaradzki, J. A. and Saika, E. M., "A Subgrid-Scale Model Based on the Estimation of Unresolved Scales of Turbulence," Physics of Fluids, Vol. 9, No. 7, Jul. 1997, pp. 2148-2164.

${ }^{59}$ Domaradzki, J. A. and Loh, K.-C., "The Subgrid-Scale Estimation Model in the Physical Space Representation," Physics of Fluids, Vol. 11, No. 8, Aug. 1999, pp. 2330-2342.

${ }^{60}$ Fureby, C. and Grinstein, F. F., "Monotonically Integrated Large Eddy Simulation," AIAA Journal, Vol. 37, No. 5, May 1999, pp. 544-556.

${ }^{61}$ Visbal, M. R. and Rizzetta, D. P., "Large-Eddy Simulation on Curvilinear Grids Using Compact Differencing and Filtering Schemes," Journal of Fluids Engineering, Vol. 124, No. 4, Dec. 2002, pp. 836-847.

${ }^{62}$ Visbal, M. R., Morgan, P. E., and Rizzetta, D. P., "An Implicit LES Approach Based on High-Order Compact Differencing and Filtering Schemes," AIAA Paper 2003-4098, Jun. 2003.

${ }^{63}$ Boris, J. P., "More for LES: A Brief Historical Perspective of MILES," Implicit Large Eddy Simulation, edited by F. F. Grinstein, L. G. Margolin, and W. J. Rider, Cambridge University Press, New York, NY, 2007, pp. 9-38.

${ }^{64}$ Grinstein, F. F., Margolin, L. G., and Rider, W. J., "A Rational for Implicit LES," Implicit Large Eddy Simulation, edited by F. Grinstein, L. Margolin, and W. Rider, Cambridge University Press, New York, NY, 2007, pp. 39-58.

${ }^{65}$ Spalart, P. R., "Direct Numerical Simualtion of a Turbulent Boundary Layer Up to $R e_{\theta}=1410$," Journal of Fluid Mechanics, Vol. 187, Feb. 1988, pp. 61-98.

${ }^{66}$ Lund, T. S., Wu, X., and Squires, K. D., "Generation of Turbulent Inflow Data for Spatially-Developing Boundary Layer Simulations," Journal of Computational Physics, Vol. 140, No. 2, Mar. 1998, pp. 233-258.

${ }^{67}$ Sagaut, P., Garnier, E., Tromeur, E., Larcheveque, L., and Labourasse, E., "Turbulent Inflow Conditions for Large-Eddy Simulation of Compressible Wall-Bounded Flows," AIAA Journal, Vol. 42, No. 3, Mar. 2004, pp. 469-477.

${ }^{68}$ Kraichnan, R. H., "Diffusion by a Random Velocity Field," Physics of Fluids, Vol. 13, No. 1, Jan. 1970, pp. 22-31.

${ }^{69}$ Lee, S., Lele, S. K., and Moin, P., "Simulation of Spatially Evolving Turbulence and the Application of Taylor's Hypothesis in Compressible Flow," Physics of Fluids A, Vol. 4, No. 7, Jul. 1992, pp. 1521-1530.

${ }^{70}$ Keating, A., Piomelli, U., and Balaras, E., "A Priori and Posterioi Tests of Inflow Conditions for Large-Eddy Simulation," Physics of Fluids, Vol. 16, No. 12, Dec 2004, pp. 4696-4712.

${ }^{71}$ Akselvoll, K. and Moin, P., "Application of the Dynamic Localization Model to Large Eddy Simulation of Turbulent Flow over a Backward-Facing Step," Engineering Applications of Large Eddy Simulation, edited by U. Piomelli and S. Ragab, American Society of Mechanical Engineers, New York, NY, 1993.

${ }^{72}$ Akselvoll, K. and Moin, P., "Large Eddy Simulation of Turbulent Confined Coannular Jets and Turbulent Flow over a Backward Facing Step," Technical Report TF-63, Thermo-Sciences Division, Department of Mechanical Engineering, Stanford University, Stanford, CA, 1995.

${ }^{73}$ Adams, N. A., "Direct Numerical Simulation of Compression Ramp Flow," Theoretical and Computational Fluid Dynamics, Vol. 12, No. 2, Sep. 1998, pp. 109-129. 
${ }^{74}$ Adams, N. A., "Direct Numerical Simulation of the Turbulent Boundary Layer along a Compression Ramp at $M=3.0$ and $R e_{\theta}=1685$," Journal of Fluid Mechanics, Vol. 420, Oct. 2000, pp. 47-83.

${ }^{75}$ Rizzetta, D. P., Visbal, M. R., and Gaitonde, D. V., "Large-Eddy Simulation of Supersonic Compression-Ramp Flow by a High-Order Method," AIAA Journal, Vol. 39, No. 12, Dec. 2001, pp. 2283-2292.

${ }^{76}$ Rizzetta, D. P. and Visbal, M. R., "Application of Large-Eddy Simulation to Supersonic Compression Ramps," AIAA Journal, Vol. 40, No. 8, Aug. 2002, pp. 1574-1581.

${ }^{77}$ Rizzetta, D. P. and Visbal, M. R., "Large-Eddy Simulation of Supersonic Cavity Flowfields Including Flow Control," AIAA Journal, Vol. 41, No. 8, Aug. 2003, pp. 1452-1462.

${ }^{78}$ Rai, M. M. and Moin, P., "Direct Numerical Simulation of Transition and Turbulence in a Spatially Evolving Boundary Layer," Journal of Computational Physics, Vol. 109, No. 2, Dec. 1993, pp. 169-192.

${ }^{79}$ Fasel, H. and Konzelmann, U., "Non-parallel Stability of a Flat-Plate Boundary Layer Using the Complete Navier-Stokes Equations," Journal of Fluid Mechanics, Vol. 221, Dec. 1990, pp. 311-347.

${ }^{80}$ Visbal, M. R., Gaitonde, D. V., and Roy, S., "Control of Transitional and Turbulent Flows Using Plasma-Based Actuators," AIAA Paper 2006-3230, Jun. 2006.

${ }^{81}$ Rizzetta, D. P. and Visbal, M. R., "Numerical Investigation of Plasma-Based Flow Control for Transitional Highly Loaded Low-Pressure Turbine," AIAA Journal, Vol. 45, No. 10, Oct. 2007, pp. 2554-2564.

${ }^{82}$ Rowley, C. W. and Colonius, T., "Discretely Nonreflecting Boundary Conditions for Linear Hyperbolic Systems," Journal of Computational Physics, Vol. 157, 2000, pp. 500-538.

${ }^{83}$ Colonius, T., Lele, S. K., and Moin, P., "Boundary Conditions for Direct Computation of Aerodynamic Sound Generation," AIAA Journal, Vol. 31, No. 9, 1993, pp. 1574-1582.

${ }^{84}$ Poinsot, T. J. and Lele, S. K., "Boundary Conditions for Direct Simulation of Compressible Viscous Flows," Journal of Computational Physics, Vol. 101, 1992, pp. 104-129.

${ }^{85}$ Giles, M. B., "Nonreflecting Boundary Conditions for Euler Equation Calculations," AIAA Journal, Vol. 28, No. 12, 1990, pp. 2050-2058.

${ }^{86}$ Freund, J. B., "Proposed Inflow/Outflow Boundary Condition for Direct Computation of Aerodynamic Sound," AIAA Journal, Vol. 35, No. 4, 1997, pp. 740-742.

${ }^{87}$ Garnier, E., Mossi, M., Sagaut, P., Comte, P., and Deville, M., "On the Use of Shock-Capturing Schemes for Large-Eddy Simulation," Journal of Computational Physics, Vol. 153, No. 2, Aug. 1999, pp. 273-311.

${ }^{88}$ Hill, D. J. and Pullin, D. I., "Hybrid Tuned Center-Difference-WENO Method for Large Eddy Simulations in the Presence of Strong Shocks," Journal of Computational Physics, Vol. 194, No. 2, Mar. 2004, pp. 435-450.

${ }^{89}$ Liu, X. D., Osher, D., and T., C., "Weighted Essentially Non-oscillatory Schemes," Journal of Computational Physics, Vol. 115, No. 1, Nov. 1994, pp. 200-212.

${ }^{90}$ Visbal, M. R. and Gaitonde, D. V., "Shock Capturing Using Compact-Difference Methods," AIAA Paper 2005-1265, Jan. 2005.

${ }^{91}$ Maas, U. and Pope, S. B., "Implementation of Simplified Chemical Kinetics based on Intrinsic Low-Dimensional Manifolds," 24th International Symposium on Combustion, 1993, pp. 103-112.

${ }^{92}$ Pepiot-Desjardins, P. and Pitsch, H., "An Efficient Error Propagation Based Reduction Method for Large Chemical Kinetic Mechanisms," Combustion and Flame, Vol. 154, No. 4, 2008, pp. 740-760.

${ }^{93}$ Peters, N., Turbulent Combustion, Cambridge University Press, 2000.

${ }^{94}$ Fureby, C., "A Comparison of Flamelet Models for Premixed Turbulent Combustion," AIAA Paper 2006-0155, Jan. 2006.

${ }^{95} \mathrm{Gao}$, F. and O'Brien, E. E., "A Large-Eddy Simulation Scheme for Turbulent Reacting Flows," Physics of Fluids A, Vol. 5, No. 6, 1993, pp. 1282-1284.

${ }^{96}$ Givi, P., "Filtered Density Function for Subgrid Scale Modeling of Turbulent Combustion," AIAA Journal, Vol. 44, No. 1, Jan. 2006, pp. 16-23.

${ }^{97}$ Girimaji, S., "Assumed $\beta$-PDF Model for Turbulent Mixing: Validation and extension to Multiple Scalar Mixing," Combustion Science and Technology, Vol. 78, 1991, pp. 1771-96.

${ }^{98}$ Givi, P., "Model Free Simulations of Turbulent Reactive Flows," Progress in Energy and Combustion Science, Vol. 15, 1989, pp. 1-107.

${ }^{99}$ Pope, S. B., "Computations of Turbulent Combustion: Progress and Challenges," Proceedings of the Combustion Institute, Vol. 23, 1990, pp. 591-612.

${ }^{100}$ Fureby, C., "Comparison of Flamelet and Finite Rate Chemistry LES for Premixed Turbulent Combustion," AIAA Paper 2007-1413, Jan. 2007.

${ }^{101}$ Colin, O., Ducros, F., Veynante, D., and Poinsot, T., "A Thickened Flame Model for Large Eddy Simulations of Turbulent Premixed Combustion," Physics of Fluids, Vol. 12, 2000, pp. 1282-1284.

${ }^{102}$ Sankaran, V. and Menon, S., "Subgrid Combustion Modeling of 3-D Premixed Flames in the Thin-Reaction-Zone Regime," Proceedings of the Combustion Institute, Vol. 30, No. 1, Jan. 2005, pp. 575-582. 


\begin{tabular}{|c|c|c|c|c|c|}
\hline \multicolumn{5}{|c|}{ REPORT DOCUMENTATION PAGE } & $\begin{array}{l}\text { Form Approved } \\
\text { OMB No. 0704-0188 }\end{array}$ \\
\hline \multicolumn{6}{|c|}{ 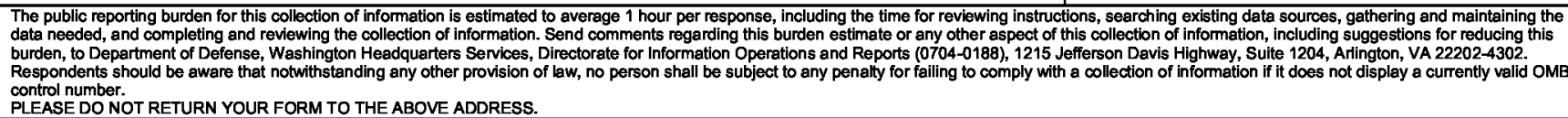 } \\
\hline \multicolumn{2}{|c|}{$\begin{array}{l}\text { 1. REPORT DATE (DD-MM-YYYY) } \\
01-07-2009\end{array}$} & \multicolumn{3}{|c|}{$\begin{array}{l}\text { 2. REPORT TYPE } \\
\text { Technical Memorandum }\end{array}$} & 3. DATES COVERED (From - To) \\
\hline \multirow{3}{*}{\multicolumn{5}{|c|}{$\begin{array}{l}\text { 4. TITLE AND SUBTITLE } \\
\text { Large-Eddy Simulation: Current Capabilities, Recommended Practices, and Future Researc }\end{array}$}} & 5a. CONTRACT NUMBER \\
\hline & & & & & 5b. GRANT NUMBER \\
\hline & & & & & 5c. PROGRAM ELEMENT NUMBER \\
\hline \multirow{3}{*}{\multicolumn{5}{|c|}{$\begin{array}{l}\text { 6. AUTHOR(S) } \\
\text { Georgiadis, Nicholas, J.; Rizzetta, Donald, P.; Fureby, Christer }\end{array}$}} & 5d. PROJECT NUMBER \\
\hline & & & & & 5e. TASK NUMBER \\
\hline & & & & & $\begin{array}{l}\text { 5f. WORK UNIT NUMBER } \\
\text { WBS } 561581.02 .08 .03 .18 .03\end{array}$ \\
\hline \multicolumn{5}{|c|}{$\begin{array}{l}\text { 7. PERFORMING ORGANIZATION NAME(S) AND ADDRESS(ES) } \\
\text { National Aeronautics and Space Administration } \\
\text { John H. Glenn Research Center at Lewis Field } \\
\text { Cleveland, Ohio } 44135-3191\end{array}$} & $\begin{array}{l}\text { 8. PERFORMING ORGANIZATION } \\
\text { REPORT NUMBER } \\
\text { E-16932 }\end{array}$ \\
\hline \multirow{2}{*}{\multicolumn{5}{|c|}{$\begin{array}{l}\text { 9. SPONSORING/MONITORING AGENCY NAME(S) AND ADDRESS(ES) } \\
\text { National Aeronautics and Space Administration } \\
\text { Washington, DC 20546-0001 }\end{array}$}} & $\begin{array}{l}\text { 10. SPONSORING/MONITOR'S } \\
\text { ACRONYM(S) } \\
\text { NASA; AIAA }\end{array}$ \\
\hline & & & & & $\begin{array}{l}\text { 11. SPONSORING/MONITORING } \\
\text { REPORT NUMBER } \\
\text { NASA/TM-2009-215616; AIAA-2009-948 }\end{array}$ \\
\hline \multicolumn{6}{|c|}{$\begin{array}{l}\text { 12. DISTRIBUTION/AVAILABILITY STATEMENT } \\
\text { Unclassified-Unlimited } \\
\text { Subject Category: } 01 \\
\text { Available electronically at http://gltrs.grc.nasa.gov } \\
\text { This publication is available from the NASA Center for AeroSpace Information, 443-757-5802 }\end{array}$} \\
\hline \multicolumn{6}{|c|}{ 13. SUPPLEMENTARY NOTES } \\
\hline \multirow{2}{*}{\multicolumn{6}{|c|}{$\begin{array}{l}\text { 14. ABSTRACT } \\
\text { This paper presents the results of an activity by the Large Eddy Simulation (LES) Working Group of the AIAA Fluid Dynamics Technical } \\
\text { Committee to (1) address the current capabilities of LES, (2) outline recommended practices and key considerations for using LES, and ( } 3 \text { ) } \\
\text { identify future research needs to advance the capabilities and reliability of LES for analysis of turbulent flows. To address the current } \\
\text { capabilities and future needs, a survey comprised of eleven questions was posed to LES Working Group members to assemble a broad range } \\
\text { of perspectives on important topics related to LES. The responses to these survey questions are summarized with the intent not to be a } \\
\text { comprehensive dictate on LES, but rather the perspective of one group on some important issues. A list of recommended practices is also } \\
\text { provided, which does not treat all aspects of a LES, but provides guidance on some of the key areas that should be considered. } \\
\text { 15. SUBJECT TERMS } \\
\text { Turbulence; Large Eddy Simulation }\end{array}$}} \\
\hline & & & & & \\
\hline \multicolumn{3}{|c|}{ 16. SECURITY CLASSIFICATION OF: } & $\begin{array}{l}\text { 17. LIMITATION OF } \\
\text { ABSTRACT }\end{array}$ & $\begin{array}{l}\text { 18. NUMBER } \\
\text { OF }\end{array}$ & $\begin{array}{l}\text { 19a. NAME OF RESPONSIBLE PERSON } \\
\text { STI Help Desk (email:help@sti.nasa.gov) }\end{array}$ \\
\hline $\begin{array}{l}\text { a. REPORT } \\
\text { U }\end{array}$ & $\begin{array}{l}\text { b. ABSTRACT } \\
\text { U }\end{array}$ & \begin{tabular}{|l|} 
c. THIS \\
PAGE \\
U
\end{tabular} & UU & $\begin{array}{l}\text { PAGES } \\
26\end{array}$ & $\begin{array}{l}\text { 19b. TELEPHONE NUMBER (Include area code) } \\
443-757-5802\end{array}$ \\
\hline
\end{tabular}



